\title{
BMJ Open Longitudinal analysis of local government spending on adult social care and carers' subjective well-being in England
}

Yanan Zhang (D) , ${ }^{1}$ Matthew R Bennett (D) , ${ }^{2}$ Sue Yeandle ${ }^{2}$

To cite: Zhang Y, Bennett MR, Yeandle S. Longitudinal analysis of local government spending on adult social care and carers' subjective wellbeing in England. BMJ Open 2021;11:e049652. doi:10.1136/ bmjopen-2021-049652

- Prepublication history and additional supplemental material for this paper are available online. To view these files, please visit the journal online (http://dx.doi.org/10.1136/ bmjopen-2021-049652).

Received 09 February 2021 Accepted 29 October 2021

A) Check for updates

(c) Author(s) (or their employer(s)) 2021. Re-use permitted under CC BY-NC. No commercial re-use. See rights and permissions. Published by BMJ.

${ }^{1}$ Oxford Institute of Population Ageing, Oxford University, Oxford, UK

${ }^{2}$ Centre for International Research on Care Labour and Equalities (CIRCLE), The University of Sheffield, Sheffield, UK

Correspondence to

Dr Yanan Zhang;

zhangyanan0918@gmail.com

\section{ABSTRACT}

Objectives Reform of England's social care system is repeatedly discussed in the context of increasing demand, rising costs and austere policies that have decreased service provision. This study investigates the association between unpaid carers' subjective well-being and local government spending on adult social care (ASC).

Setting and participants Our sample consists of 110 188 observations on 29174 adults in England from the 2004-2007 British Household Panel Survey and the 2009-2018 UK Household Longitudinal Study. The data on local authorities' spending on ASC where participants live is derived from the publications Personal Social Care Expenditure and Unit Costs (2004-2016); and ASC Activity and Finance Report England (2016-2018).

Outcome measures Subjective well-being is measured by the 12-item version of the General Health Questionnaire (GHQ-12) and 12-item version of the Mental Component Summary (MCS-12). We applied fixed-effects linear models to investigate the moderating effect of ASC spending on the association between subjective well-being and caring, controlling for a range of socioeconomic and demographic variables

Results Carers have a lower level of subjective wellbeing compared with non-carers, evident in their higher average GHQ-12 Likert score ( $\beta=2.727795 \% \mathrm{Cl} 0.2547$ to 5.2008). Differences in the subjective well-being of carers and non-carers decrease with local government spending on ASC. Subjective well-being for carers was at a similar level to that of non-carers in high ASC spending local authorities (GHQ-12: $-0.012395 \% \mathrm{Cl}-0.2185$ to 0.1938 , MCS-12: $0.034795 \% \mathrm{Cl}-0.3403$ to 0.4098 ) and lower in other areas (GHQ-12: $0.189395 \% \mathrm{Cl} 0.0680$ to 0.3107 , MCS-12: $-0.290695 \% \mathrm{Cl}-0.5107$ to -0.0705$)$. The moderating effect of ASC spending is found among people who care for $35+$ hours per week.

Conclusion Government spending on ASC protects unpaid carers' well-being, and people providing more than 35 weekly hours of unpaid care are more likely to benefit from the current social care system.

\section{INTRODUCTION}

A growing proportion of adults in England need long-term care services or support to perform daily activities: an outcome of population ageing and other factors. ${ }^{1}$ Most

\section{Strengths and limitations of this study}

This is the first study to investigate the effectiveness of local government spending on England's current adult social care (ASC) system in terms of protecting unpaid carers' subjective well-being.

- Fixed-effects (FE) linear models are used to estimate the impact of local government ASC spending on carers' and non-carers' 12 -item version of the General Health Questionnaire (GHQ-12) Likert scores and the Mental Component Summary (MCS12) scores.

- Robustness checks include: use of FE based instrumental variable estimators; different measurements of government spending (local government ASC spending per client); and various other outcomes (depression, defined as GHQ-12 caseness is equal to or larger than 3).

- Due to a lack of data, we cannot identify specific services that improve unpaid carers' subjective well-being.

- The sample covers only 122 of England's 152 councils with adult social services responsibilities.

care is provided (unpaid) by family, friends and neighbours. However, supporting the care needs of eligible persons-based on a needs (and means) assessment-is a statutory responsibility of local authorities (LAs), specifically those designated as CASSRs (councils with adult social services responsibilities). Some individuals also purchase care privately or obtain support through voluntary organisations. In 2016-2017, English LAs' gross current expenditure on adult social care (ASC) was $£ 17.5$ billion. ${ }^{2}$ A recent estimate of the total annual value of unpaid care (provided by adults) was $£ 108$ billion (England). ${ }^{3}$

In the current context of rising demand for care and severe constraints on LA ASC budgets, carers play an increasingly important role. Providing care could be positively associated with carers' well-being 
due to the increasing closeness between them and care recipient and satisfaction from fulfilling this role. ${ }^{45}$ Caring activities also consume carers' time and energy, often limit their paid work and social activities, and are physically, psychologically and emotionally demanding. ${ }^{67}$ The negative impact of caring on carers' financial situation, physical and mental well-being and familial relationships is well documented in the international literature. ${ }^{89}$

Despite increasing awareness, recognition and support for carers, and LAs' greater role in supporting them following the Care Act 2014, only a small number of carers receive carer-specific support. The ASC services LAs provide for people with care and support needs play an important role in alleviating pressures on carers, yet little is currently known about how carers benefit from public expenditure designed to support them. Local variations in ASC provision have been explored using data on ASC expenditure, numbers of LA-supported nursing home and residential care places and hours of LA-funded homecare. ${ }^{1011}$ Existing studies have used such data to assess how the provision of publicly funded ASC affects mortality, unmet need, use of A\&E services and hospital admission rates. However, impacts on carers have hitherto been neglected. ${ }^{11-13}$

Our study examined the extent to which LA ASC spending affects the subjective well-being of unpaid carers. Carers' well-being is an explicit focus of the Care Act 2014, vital for the operation of England's care system, and has implications for future demand for ASC. This study adds to the existing evidence base, can inform future planning of ASC, and is extremely timely, given Government plans for ASC reform.

\section{METHODS}

\section{Study design and participants}

Our national analysis uses the British Household Panel Survey (BHPS, 2004-2007), the UK Household Longitudinal Study (UKHLS, 2009-2018) and official data for England on Personal Social Care Expenditure and Unit Costs (2004-2016) and ASC Activity and Finance (2016-2018). ${ }^{14-16}$ Individual characteristics, including subjective well-being and caring activities, are from the English samples of the BHPS and UKHLS. Current gross spending on ASC for relevant English LAs is from the Personal Social Care Expenditure and Unit Costs (PSSEX1, 2004-2016), the ASC Finance Return and the Short and Long Term collection (2016-2018).

For the information on the location (LA district) of the participants in the BHPS and UKHLS, we obtained Special Licence Access from the UK Data Service (SN 6666). ${ }^{17} \mathrm{We}$ merged individual-level survey data and LA ASC expenditure data using district codes. Gross spending on ASC at the LA level is not available for the 2008/2009 financial year, resulting in a gap in our analysis.

\section{Procedures}

The key outcome of interest for our analysis is subjective well-being, measured by the 12-item version of the General Health Questionnaire (GHQ-12) and the Mental Component Summary of the Short-Form 12 Health Survey (MCS-12) ${ }^{18-20}$ The GHQ-12 Likert score ranges from 0 to 36, and a higher score represents more symptoms of depression or anxiety. The MCS-12 is a continuous score with a range between 0 and 100; here a higher score indicates a better mental health status.

Individuals were identified as (unpaid) carers if they answered 'yes' to either of the following questions:

'Is there anyone living with you who is sick, disabled or elderly whom you look after or give special help to (for example, a sick, disabled or elderly relative, husband, wife or friend etc.)?'

'Do you provide some regular service or help for any sick, disabled or elderly person not living with you?'

\section{Statistical analysis}

We applied multivariate regression analysis to investigate the moderating effects of LA ASC spending. We observe the difference in subjective well-being between people with and without caring responsibilities, and investigate how these differences vary according to government ASC spending in the following equation:

$$
\begin{aligned}
& \operatorname{SWB}_{\mathrm{i}, \mathrm{j}, \mathrm{t}}=\partial_{0}+\partial_{1} \operatorname{Care}_{\mathrm{i}, \mathrm{j}, \mathrm{t}}+\partial_{2} \mathrm{ASC}_{\mathrm{j}, \mathrm{t}}+\partial_{3} \operatorname{Care}_{\mathrm{i}, \mathrm{j}, \mathrm{t}} * \operatorname{ASC}_{\mathrm{j}, \mathrm{t}} \\
& +\partial_{4} * \operatorname{Controls}_{\mathrm{i}, \mathrm{j}, \mathrm{t}}+\mathrm{u}_{\mathrm{i}}+\mathrm{u}_{\mathrm{j}}+\mathrm{u}_{\mathrm{t}}+\epsilon_{\mathrm{i}, \mathrm{j}, \mathrm{t}}
\end{aligned}
$$

$S W B_{i, j, t}$ is one of two subjective well-being indicators (GHQ-12 Likert and MCS-12 score) for individual $i$, living in LA $j$, in year $t$. Unpaid care is a dummy variable equal to one if the respondent is an unpaid carer, and to zero if they are not. $A S C_{j, t}$ is the natural logarithm of real aggregate government spending on ASC for LA $j$ in year $t$ (the size of the LA is controlled by including variables for the local population and its age structure). The logarithm transformation reduces heteroskedasticity and skewness (variability of data) and improves the interpretability of the coefficient, for example, the changes in subjective well-being associated with a 1\% change in ASC spending. In areas where the spending on ASC is higher, the infrastructure of social care services is in general better: more services are offered and residents can more readily access services. As a robustness check, we use government ASC spending per client to measure social care services (as detailed in the Discussion section). The difference in subjective well-being between carers and non-carers is indicated by $\partial_{1}$, and $\partial_{3}$ is the coefficient on the interaction of Care and ASC, which shows the moderating effects of local government ASC spending on the impact of caring on subjective well-being.

Control variables for individuals include educational attainment, age, marital status, financial status, employment status, health status and household size; for LAs we use dependency ratios, total population and Gross Value Added (GVA). $u_{i}, u_{j}$, and $u_{t}$, represent the 
individual-specific time-invariant effect, LA effect, and business cycle effect respectively. $\epsilon_{i, j, t}$ is the idiosyncratic error term.

We conducted a sensitivity analysis by grouping LAs based on their spending on ASC. We categorise those with spending in the top $25 \%$ of the distribution as having ' $h i g h$ ' LA ASC spending and in the bottom $75 \%$ as 'lower. We are interested in the difference in the impact of caring on subjective well-being between LAs with ' $h i g h$ ' and 'lower'spending on ASC. To this end, we estimate the following model:

$$
\begin{aligned}
& \operatorname{SWB}_{\mathrm{i}, \mathrm{j}, \mathrm{t}}=\beta_{0}+\beta_{1} \operatorname{Care}_{\mathrm{i}, \mathrm{j}, \mathrm{t}} * \operatorname{HighASC}_{\mathrm{j}, \mathrm{t}} \\
& +\beta_{2} \operatorname{Care}_{\mathrm{i}, \mathrm{j}, \mathrm{t}} *\left(1-\operatorname{HighASC}_{\mathrm{j}, \mathrm{t}}\right)+\beta_{3} \operatorname{HighASC}_{\mathrm{j}, \mathrm{t}} \\
& +\beta_{4} \mathrm{ASC}_{\mathrm{j}, \mathrm{t}}+\beta_{5} * \operatorname{Controls}_{\mathrm{i}, \mathrm{j}, \mathrm{t}}+\mathrm{u}_{\mathrm{i}}+\mathrm{u}_{\mathrm{j}}+\mathrm{u}_{\mathrm{t}}+\epsilon_{\mathrm{i}, \mathrm{j}, \mathrm{t}}
\end{aligned}
$$

$\beta_{1}\left(\beta_{2}\right)$ represents the difference in subjective wellbeing between those with and without care responsibilities in areas with 'high' ('lower') LA spending on ASC. If carers benefit significantly from ASC spending provided by their LA, this difference will be less in 'high'spending areas $\left(\left|\beta_{1}\right|<\left|\beta_{2}\right|\right)$. The dataset provided information on hours of unpaid care provided per week, with the following response categories: $0-4,5-9,10-19,20-34$, 35-49, 50-99 and 100+ hours per week. We classify carers based on caring intensity: carers have a ' $h i g h$ ' intensity of care if they spend 35+hours per week on unpaid care. We use a 35-hour cut-off because this is: (1) the hours of care threshold for claiming Carer's Allowance and (2) equivalent to weekly hours in full-time employment. We then investigate the varying effects of LA ASC spending on carers with different levels of caring intensity.

\section{Patient and public involvement}

Our analysis is based on secondary data, and all data are publicly available. The study design and analytical interpretations involved no direct contact with patients or the public.

\section{RESULTS}

Table 1 shows that our sample consists of 110188 observations between 2004 and 2018 for 29174 individuals aged 15 and over in 122 LAs. Among them, 19194 (17.42\%) are people who provide care for someone who is sick, disabled, or elderly. Compared with non-carers, carers' subjective well-being is significantly lower. The average GHQ-12 Likert score is 11.85 for carers and 11.03 for non-carers. The MCS-12 score of carers is 48.25 , lower than non-carers' score of 49.23. The percentage of individuals whose GHQ-12 caseness is greater than or equal to 3 (indicating depression) is $28.46 \%$ (5463) for carers and $23.69 \%$ (21 556) for non-carers. Carers tend to be female, married, disabled, older and retired, and have less income and live with more household members. They are less likely to have a degree, to be widowed or to have paid employment.

\section{LA gross ASC spending and mental well-being}

Figure 1 represents the relationship between unpaid care and mental well-being across gross LA ASC spending (full model results are given in online supplemental appendix I). The figure shows that the negative impact of providing care on subjective mental well-being decreases with level of LA spending on ASC. That is, higher spending on ASC protects against poor mental well-being among carers. Figure 1A demonstrates that, all else being equal, carers' GHQ-12 Likert score is 0.7729 (95\% CI 0.1581 to 1.3877 ) higher (indicating poorer well-being) than the score for non-carers in LAs with $£ 6 \mathrm{~m}$ ASC spending. In contrast, carers and non-carers have a similar GHQ-12 score in areas where LA ASC spending is $£ 199 \mathrm{~m}$ ( $\beta=-0.013595 \% \mathrm{CI}-0.1933$ to 0.1663$)$. Note that LA ASC spending is a function of many factors including LA size, care need, composition of the local system, etc. We have adjusted our models with a number of LA covariates (year dummies, dependency ratio, total population and GVA) to take account of these variations and differences in local spending.

Figure 1B represents the relationship between unpaid care and MCS-12 across gross LA ASC spending. The difference in the MCS-12 score between carers and noncarers declines as LA ASC spending increases. In LA areas with $£ 6$ m ASC spending, carers have a 1.2417 lower MCS-12 score (-2.400 to -0.0834) compared with noncarers. However, carers' and non-carers' MCS-12 score is not statistically different $(-0.1460-0.3530$ to 0.0610$)$ in LAs where ASC spending is £121 million.

\section{High and lower LA ASC spending and mental well-being}

Figure 2 represents the relationship between unpaid care and mental well-being in 'high' (LAs with ASC spending in the top $25 \%$ of the distribution) and 'lower' (LAs with spending in the bottom $75 \% \%$ of the distribution) spending LAs (full model results are given in online supplemental appendix II). Carers report GHQ-12 Likert scores that are 0.1893 ( 0.0680 to 0.3107 ) higher (meaning well-being is worse) than non-carers in LAs with lower ASC spending (figure 2A). In LAs with high ASC spending, however, the GHQ-12 Likert score for carers is not statistically different from that for non-carers $(-0.0123-0.2185$ to 0.1938). In LAs where ASC spending is lower, carers report a 0.2906 lower MCS-12 score $(-0.5107$ to -0.0705$)$ than non-carers (figure 2B). There is no significant difference in the MCS-12 scores of carers and non-carers in high ASC spending LAs (0.0347 -0.3403 to 0.4098).

\section{Caring intensity, LA ASC spending and mental well-being}

Figure 3 represents the relationship between caring intensity, gross LA ASC spending and GHQ-12 Likert Score (full model results are given in online supplemental appendix III). We differentiate carers by their level of caring intensity to investigate variation in the effect of LA ASC spending on carers' well-being. Figure 3A shows that carers who care intensively (35+ hours per week) report higher GHQ-12 Likert scores than non-carers (0.8414 0.4294 to 1.2534) in LAs where ASC spend is lower. Being a carer is not significantly associated 
Table 1 Data description

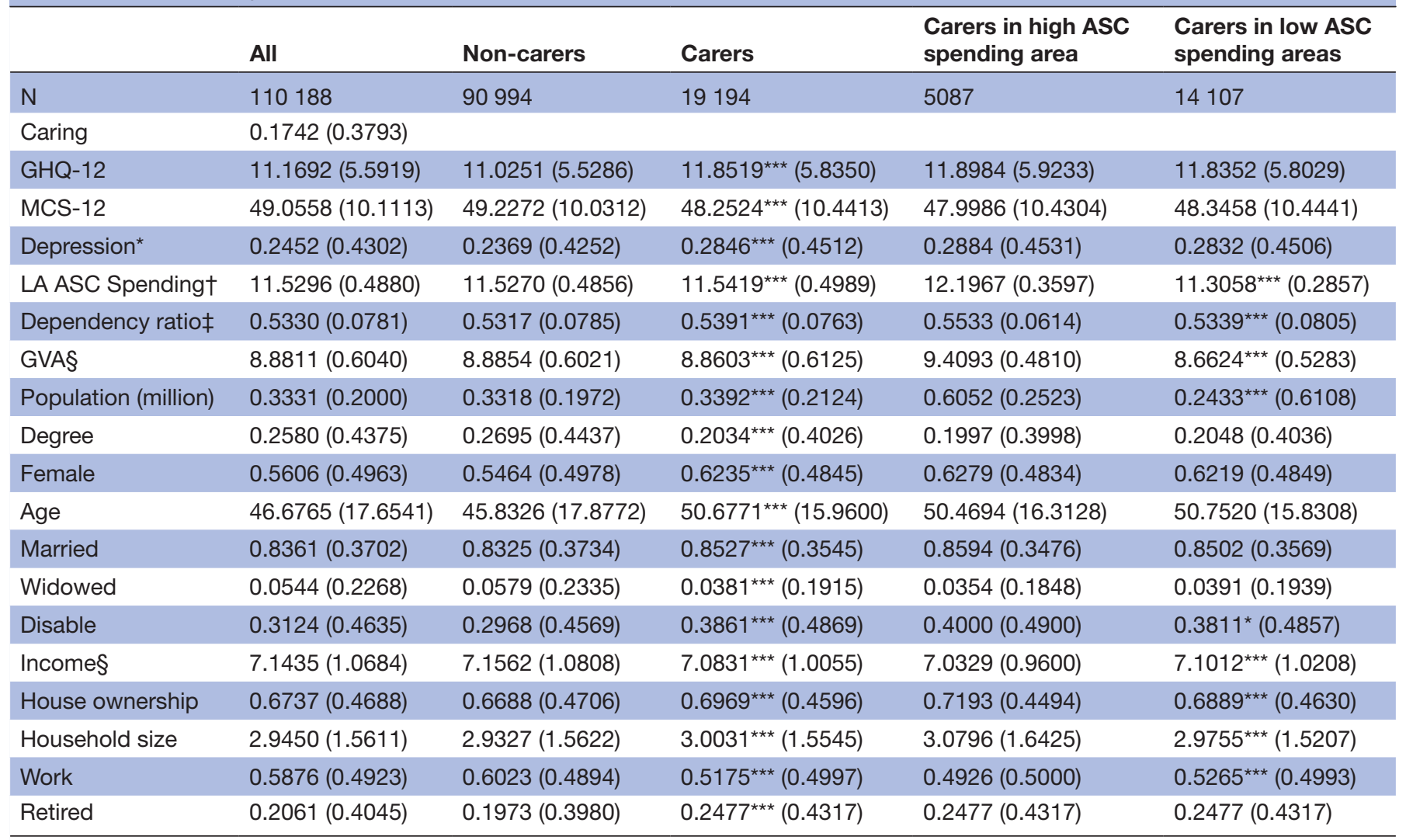

Data are $n$, and mean (SE).

Significance is indicated to the $0.1 \%$ level $\left(^{(\star \star}\right), 1 \%$ level $\left({ }^{\star *}\right)$ and $5 \%$ level $\left({ }^{\star}\right)$.

*Depression is defined as GHQ-12 Caseness is equal to or larger than 3.

†LA ASC Spending is the natural logarithm of real government spending on adult social care. The real government spending is deflated at the 2018 price and the unit is $£ 1000$.

fDependency ratio is the ratio of the number of population aged between $0-15$ and $65+$ to the working-age population.

§GVA (Income) is the natural logarithm of real GVA (personal monthly income). The GVA (income) is deflated at the 2018 price and the unit is $£ m(£ 1)$.

ASC, adult social care; GHQ-12, 12-item version of the General Health Questionnaire; GVA, Gross Value Added; LAs, local authorities; MCS-12, 12-item version of the Mental Component Summary.

with a lower level of mental well-being in high ASC spending areas $(0.3554-0.2714$ to 0.9823$)$, however. Figure 3B shows that people providing care for less than 35 hours per week and non-carers report similar GHQ-12 Likert scores in all LA areas (both LAs with lower ASC spending (0.0562 -0.0718 to $0.1842)$ and LAs with high ASC spending (-0.0641 -0.2834 to 0.1552$)$ ).

Figure 4 represents the relationship between caring intensity, gross LA ASC spending and MCS-12 score (full model results are given in online supplemental appendix IV). Compared with non-carers, carers providing 35+ hours of care per week report a 1.4247 lower MCS-12 score (-2.1832 to -0.6661$)$ in LAs with lower ASC spending (figure 4A). In high ASC spending areas, however, people caring intensively have an MCS-12 score similar to that of non-carers $(-0.7949-2.1415$ to 0.5517$)$. Providing care for less than 35 hours per week is not related to MCS-12 score (figure 4B). People who care for less than 35 hours per week and non-carers have similar MCS-12 scores in areas with both high $(0.1300-0.2532$ to 0.5132$)$ and lower
(-0.0489 -0.2769 to 0.1815$)$ local government spending on ASC.

\section{DISCUSSION}

Our analysis covers a sample of 29174 individuals across 122 LAs responsible for adult social services in England between 2004 and 2018. Other literature has shown that providing care is associated with negative subjective well-being, but to the best of our knowledge how this is affected by expenditure on ASC has not previously been investigated..$^{21-23}$

We found that high LA spending on ASC reduces the negative association between providing unpaid care and subjective well-being. We consider ASC spending a suitable proxy for provision of ASC services in an LA area, and thus conclude that such services are important in alleviating pressures on carers. Services may be provided directly to carers ('carer-specific services') or can be services for those they care for-people who need 

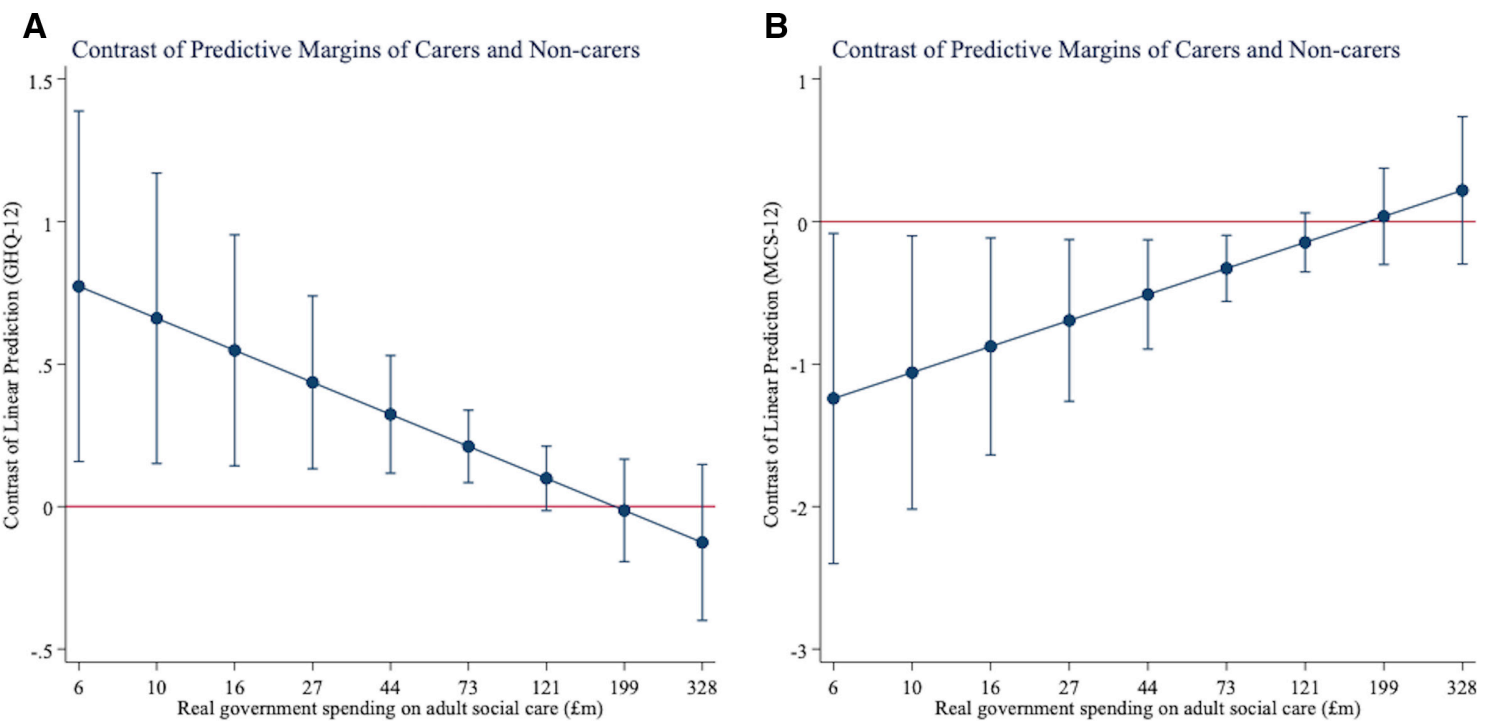

Figure 1 Subjective well-being and caring by government spending on ASC. The marginal effects of caring on GHQ-12 and MCS-12 are fixed-effects estimates. Error bars show 95\% Cl. Age, educational attainment, marital status, disability, income, household ownership, household size, employment status, the regional dependency ratio, population, GVA and time dummies are controlled. Full model results are given in online supplemental appendix I. ASC, adult social care; GHQ-12, 12-item version of the General Health Questionnaire; GVA, Gross Value Added; MCS-12, 12-item version of the Mental Component Summary.

support to manage daily activities (comprising services to working age adults with disabilities and to older people with support needs). This finding is confirmed by the fact that the difference between the reported subjective wellbeing of carers and non-carers is larger in areas where LA ASC expenditure is lower than our definition of 'high' ASC spending.

We also find that LA ASC spending lowers the negative impact of high intensity caring on carers' subjective wellbeing. The austerity measures introduced by national

A

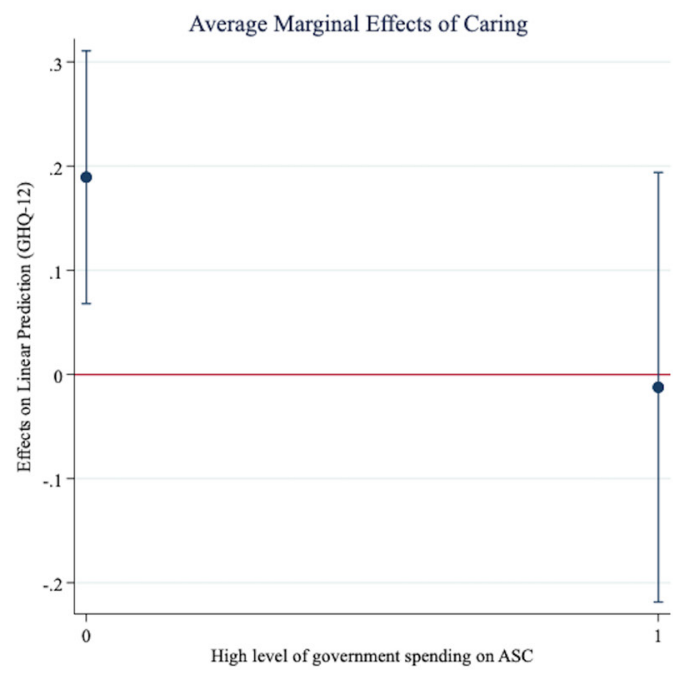

government in England from 2010 in response to the 2008 financial crisis led to major reductions in LA budgets over most of the ensuing decade. ${ }^{24}{ }^{25}$ At the same time, demand for ASC was rising, as the size of the 'oldest old' population and incidence of poor health and disability in the total adult population rose, widening the gap between demand and provision of ASC. ${ }^{36}$ LAs in England allocate their resources based on needs and means testing, so it is not surprising that people caring intensively are the ones demonstrably affected by variations in ASC expenditure.

B

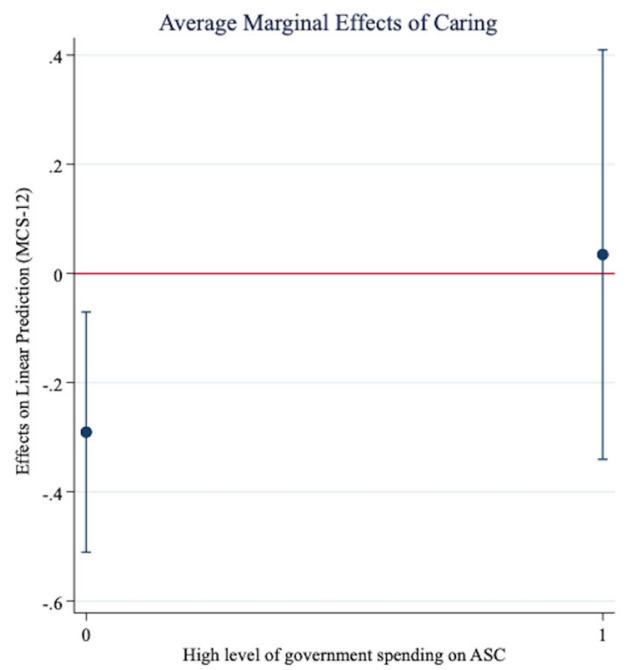

Figure 2 Subjective well-being and caring-differentiating areas by government ASC spending. The marginal effects of caring on GHQ-12 and MCS-12 are fixed-effects estimates. Error bars show 95\% Cl. Age, educational attainment, marital status, disability, income, household ownership, household size, employment status, the regional dependency ratio, population, GVA and time dummies are controlled. Full model results are given in online supplemental appendix II. ASC, adult social care; GHQ12, 12-item version of the General Health Questionnaire; GVA, Gross Value Added; MCS-12, 12-item version of the Mental Component Summary. 
A

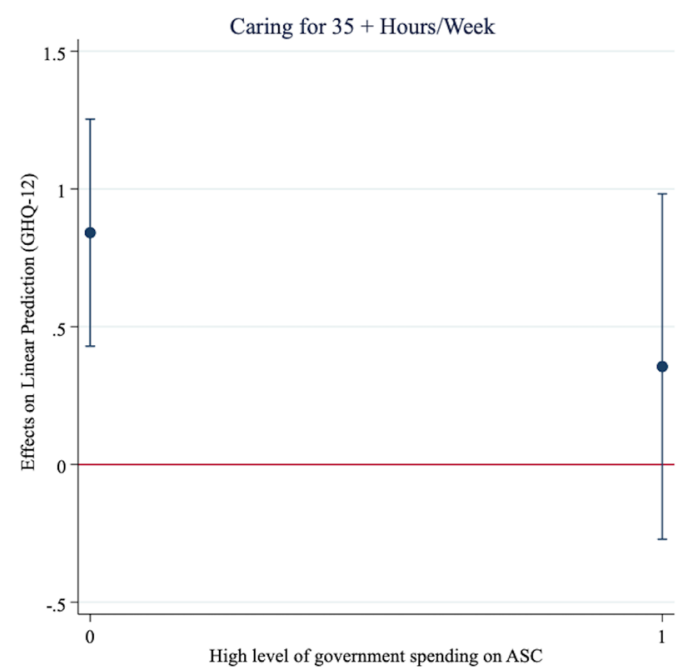

B

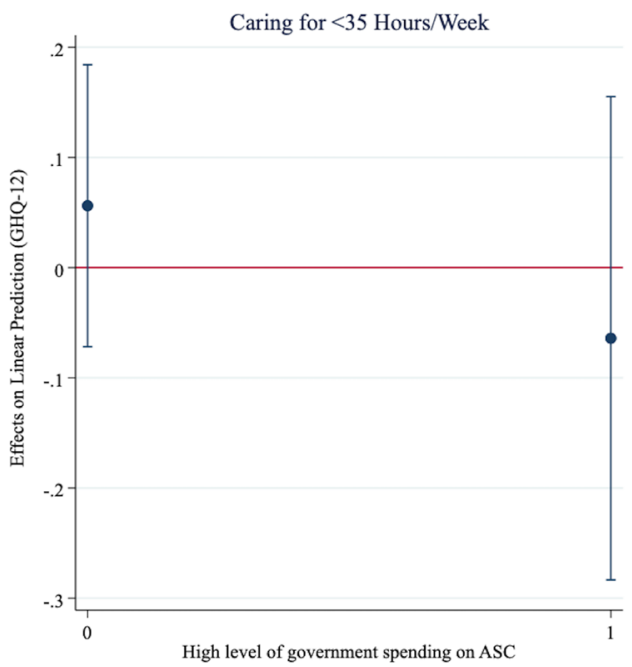

Figure 3 GHQ-12 and caring-differentiating carers with caring intensity. The marginal effects of caring are fixed-effects estimators. Error bars show 95\% Cl. Age, educational attainment, marital status, disability, income, household ownership, household size, employment status, the regional dependency ratio, population, GVA and time dummies are controlled. Full model results are given in online supplemental appendix III. ASC, adult social care; GHQ-12, 12-item version of the General Health Questionnaire; GVA, Gross Value Added.

It also seems likely that subjective well-being among carers is an outcome primarily of the intensity, rather than the incidence of caring.

Our study has some important limitations. Foremost is the absence of information on the support received by carers at the individual level. Such data are not currently available but are vital for investigation of how effective social care services are for carers. Likewise, we were unable to explore the relationship with receiving benefits (eg, Carer's Allowance) or having family support and how

A

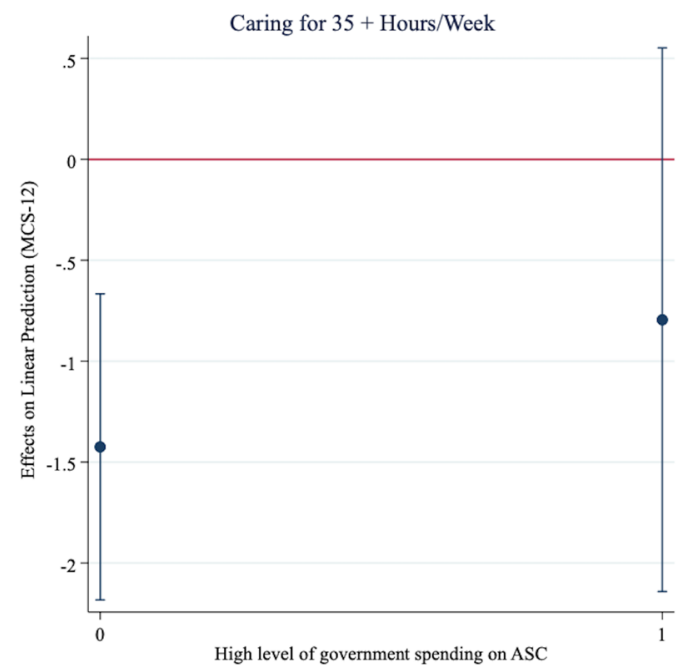

these factors impacted well-being. Second, our analysis does not distinguish between ASC services provided to carers and those provided to adults with care and support needs. This is partly due to the very limited availability of LA-funded carer-specific services in England. Studies have shown positive effects on carers' well-being from time-limited policy interventions, so this should also be a focus of future studies. ${ }^{27}$ Finally, the dataset we used covered only 122 of England's 152 LAs with adult social services responsibilities.

B

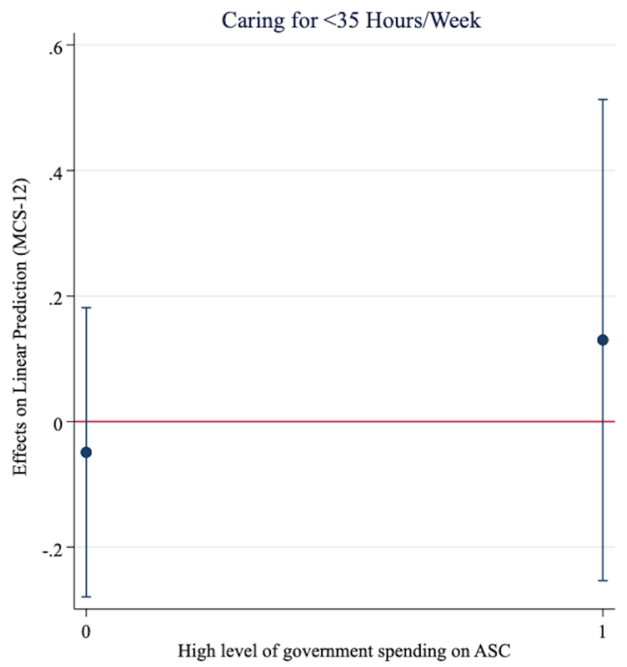

Figure 4 MCS-12 and caring-differentiating carers with caring intensity. The marginal effects of caring are fixed-effects estimators. Error bars show 95\% Cl. Age, educational attainment, marital status, disability, income, household ownership, household size, employment status, the regional dependency ratio, population, GVA and time dummies are controlled. Full model results are given in online supplemental appendix IV. ASC, adult social care; GVA, Gross Value Added; MCS-12, 12-item version of the Mental Component Summary. 
Future research should explore care intensity levels, carer-care recipient relationships, and the impact of the care-recipient's type of illness or disability on the relationship between ASC spending and well-being. Highintensity caring was defined as $35+$ hours per week in this study, but future work could explore other cut-off points and the point at which there is a moderating effect of ASC spending. This extension would also supplement the literature which shows that low levels of unpaid caring are associated with positive well-being benefits and that well-being can be improved through increased closeness between carer and care recipient and/or a sense of purpose and/or of fulfilling one's duty. ${ }^{4528-33}$ Lastly, it would be valuable to explore the relationship between carers and care recipients and the conditions/circumstances of the care recipient, factors also known to impact well-being. ${ }^{23}$ 34-38

We subjected our analysis to a wide range of relevant robustness checks. To investigate the effectiveness of ASC expenditure on improving carers' well-being, we combined data available at individual and LA levels. Our robustness checks included using a different well-being measure; depression (see online supplemental appendix V). The CASSRs cover localities of vastly different population sizes with very different population characteristics. As robustness checks, LA spending on ASC per client was used as a measurement for the care system. We estimated fixed-effects models to control for unobserved characteristics and eliminate any potential endogeneity caused by omitted and time-invariant variables. There could be omitted variables that are not time-invariant and that affect both government spending on ASC and individual subjective well-being, such as LA spending on other services, financial support received by carers, and the health status of care recipients (which may cause carers concern). For this reason, fixed-effects Instrumental Variable estimators were applied (see online supplemental appendix VI). We also conducted further analyses that controlled for LA spending on transportation services, housing services, non-ASC service expenditure and nonASC total expenditure (see online supplemental Appendices VII and VIII); these did not affect our findings. People may provide care to someone living in a different LA and the subjective well-being of those carers could be impacted by ASC services in both LAs. Additionally, women are found to be more likely to seek support for mental health. ${ }^{39}$ For these reasons, our robustness checks restrict our sample to women who provide care to a co-resident person (see online supplemental appendix IX). All the results consistently show a moderating effect of government ASC spending on the negative impact of caring on carers' subjective well-being.

\section{CONCLUSION}

Unpaid carers play a crucial role in England's social care system. This is especially the case when LAs are struggling to support assessed needs, and in the context of rising 'unmet need'. Carers' ability to provide support to those they care for is necessarily affected by their own mental and psychological health. ${ }^{40}$ Our analyses show that LA spending on ASC can moderate the negative impact of care on mental well-being.

Reductions in LA ASC spending in the past decade reduced carers' subjective well-being. This will have led to additional pressures on the nationwide health and social care system. ${ }^{41}$ In the future, demand for publiclyfunded care could rise as a consequence of increases in carers' poor subjective well-being. ${ }^{42}$ The high and rising incidence of unpaid caring makes providing adequate support that is effective for unpaid carers crucial. ${ }^{43}$ LAs need resources that enable them to provide support and services known to be effective in alleviating the pressures carers often face.

As the UK government is forced to confront England's ongoing crisis of care, a fuller understanding of the role and experience of carers will be nothing less than vital. Funding reform is undoubtedly needed, but a redesign of services and support in order to take account of what families and communities contribute, and of their need for support, will be equally important. ${ }^{44}$

\section{Twitter Yanan Zhang @DrYananZhang}

Acknowledgements The authors gratefully acknowledge the support of the Economic and Social Research Council (award ES/P009255/1, Sustainable Care: connecting people and systems, 2017-2021, Principal Investigator Sue Yeandle, University of Sheffield).

Contributors The research was designed by YZ, MRB and SY. Data analysis was performed by YZ. All authors contributed to the drafting and revision of the paper. All authors are in approval of this version of the manuscript and agree to be held accountable for all aspects of the work. As the manuscript guarantor, YZ accepts full responsibility for the finished work and the conduct of the study, has access to the data, and controls the decision to publish.

Funding This work was supported by the Economic and Social Research Council (grant number: ES/P009255/1). YZ, MRB and SY were funded by the Economic and Social Research Council.

Competing interests None declared.

Patient consent for publication Not applicable.

Ethics approval The BHPS, the UKHLS and official data for England on Personal Social Care Expenditure and Unit Costs and Adult Social Care Activity and Finance are publicly available, and both of the survey data were deidentified. Therefore, ethical approval and informed consent were not required in this study.

Provenance and peer review Not commissioned; externally peer reviewed.

Data availability statement Data are available in a public, open access repository.

Supplemental material This content has been supplied by the author(s). It has not been vetted by BMJ Publishing Group Limited (BMJ) and may not have been peer-reviewed. Any opinions or recommendations discussed are solely those of the author(s) and are not endorsed by BMJ. BMJ disclaims all liability and responsibility arising from any reliance placed on the content. Where the content includes any translated material, BMJ does not warrant the accuracy and reliability of the translations (including but not limited to local regulations, clinical guidelines, terminology, drug names and drug dosages), and is not responsible for any error and/or omissions arising from translation and adaptation or otherwise.

Open access This is an open access article distributed in accordance with the Creative Commons Attribution Non Commercial (CC BY-NC 4.0) license, which permits others to distribute, remix, adapt, build upon this work non-commercially, and license their derivative works on different terms, provided the original work is properly cited, appropriate credit is given, any changes made indicated, and the use is non-commercial. See: http://creativecommons.org/licenses/by-nc/4.0/. 
ORCID iDs

Yanan Zhang http://orcid.org/0000-0003-3836-4232

Matthew R Bennett http://orcid.org/0000-0002-9523-6053

\section{REFERENCES}

1 Spiers G, Matthews FE, Moffatt S, et al. Impact of social care supply on healthcare utilisation by older adults: a systematic review and meta-analysis. Age Ageing 2019;48:57-66.

2 NHS Digital. Adult social care activity and financial report, England 2016-17, 2017. Available: https://digital.nhs.uk/data-and-information/ publications/statistical/adult-social-care-activity-and-finance-report/ adult-social-care-activity-and-finance-report-england-2016-17 [Accessed 24 Oct 2020].

3 Buckner L, Yeandle S. Valuing carers 2015 The rising value of carers' support, 2015. Available. Available: https://www.carersuk.org/forprofessionals/policy/policy-library/valuing-carers-2015 [Accessed 24 Oct 2020].

4 Kramer BJ. Gain in the caregiving experience: where are we? what next? Gerontologist 1997:37:218-32.

5 Litwin H, Stoeckel KJ, Roll A. Relationship status and depressive symptoms among older co-resident caregivers. Aging Ment Health 2014;18:225-31.

6 Stephens MA, Townsend AL, Martire LM, et al. Balancing parent care with other roles: interrole conflict of adult daughter caregivers. $J$ Gerontol B Psychol Sci Soc Sci 2001;56:P24-34.

7 Verbakel E. Informal caregiving and well-being in Europe: what can ease the negative consequences for caregivers? J Eur Soc Policy 2014;24:424-41.

8 Bom J, Bakx P, Schut F, et al. The impact of informal caregiving for older adults on the health of various types of caregivers: a systematic review. Gerontologist 2019;59:e629-42.

9 Shooshtari S, Duncan KA, Roger K, et al. Care-related out-of-pocket spending and caregiving consequences: results from a Canadian population-based study. J Fam Econ Issues 2017;38:405-20.

10 Watkins J, Wulaningsih W, Da Zhou C, Zhou CD, et al. Effects of health and social care spending constraints on mortality in England: a time trend analysis. BMJ Open 2017;7:e017722.

11 Fernandez JL, Forder J. Consequences of local variations in social care on the performance of the acute health care sector. Appl Econ 2008;40:1503-18.

12 Iparraguirre JL. Reductions in local government spending on community-based social care and unmet social care needs of older people in England. The Journal of the Economics of Ageing 2017;17.

13 Seamer P, Brake S, Moore P, et al. Did government spending cuts to social care for older people lead to an increase in emergency hospital admissions? an ecological study, England 2005-2016. BMJ Open 2019;9:e024577

14 University of Essex, Institute for Social and Economic Research. Understanding Society: Waves 1-9, 2009-2018 and Harmonised BHPS: Waves 1-18, 1991-2009, 2019. [data collection]. 12th Edition. UK Data Service. SN: 6614

15 NHS Digital. Personal social service: expenditure and unit costs, England, 2004-2016, 2016. Available: https://digital.nhs.uk/dataand-information/publications/statistical/personal-social-servicesexpenditure-and-unit-costs [Accessed 24 Oct 2020].

16 NHS Digital. Adult social care activity and financial report, England, 2016-2018, 2018. Available: https://digital.nhs.uk/data-andinformation/publications/statistical/adult-social-care-activity-andfinance-report [Accessed 24 Oct 2020].

17 University of Essex, Institute for Social and Economic Research. Understanding Society: Waves 1-9, 2009-2018 and Harmonised BHPS: Waves 1-18, 1991-2009: Special Licence Access, Local Authority District, 2019. [data collection]. 11th Edition. UK Data Service. SN: 6666.

18 Jackson $\mathrm{C}$. The general health questionnaire. Occup Med 2007;57:79

19 McCabe CJ, Thomas KJ, Brazier JE, et al. Measuring the mental health status of a population: a comparison of the GHQ-12 and the SF-36 (MHI-5). British Journal of Psychiatry 1996;169:517-21.
20 Gill SC, Butterworth P, Rodgers B, et al. Validity of the mental health component scale of the 12-Item short-form health survey (MCS-12) as measure of common mental disorders in the general population. Psychiatry Res 2007;152:63-71.

21 Pinquart M, Sörensen S. Differences between caregivers and noncaregivers in psychological health and physical health: a metaanalysis. Psychol Aging 2003:18:250-67.

22 Arbel I, Bingham KS, Dawson DR. A scoping review of literature on sex and gender differences among dementia spousal caregivers. Gerontologist 2019;59:e802-15.

23 Penning MJ, Wu Z. Caregiver stress and mental health: impact of caregiving relationship and gender. Gerontologist 2016;56:1102-13.

24 Gray M, Barford A. The depths of the cuts: the uneven geography of local government austerity. Cambridge Journal of Regions, Economy and Society 2018;11:541-63.

25 Glasby J, Zhang Y, Bennett MR, et al. A lost decade? A renewed case for adult social care reform in England. J Soc Policy 2021;50:406-37.

26 Pickard L. A growing care gap? the supply of unpaid care for older people by their adult children in England to 2032. Ageing Soc 2015;35:96-123.

27 Yeandle S, Wigfield A. New Approaches to Supporting Carers' Health and Well-being: evidence from the National Carers' Strategy Demonstrator Sites programme, 2011. Available: http://wels.open.ac. uk/research-project/caren/node/2077 [Accessed 24 Oct 2020].

28 van Campen $\mathrm{C}$, de Boer $\mathrm{AH}$, ledema J. Are informal caregivers less happy than noncaregivers? Happiness and the intensity of caregiving in combination with paid and voluntary work. Scand J Caring Sci 2013;27:44-50

29 Lundh U. Family carers. 1: difficulties and levels of support in Sweden. Br J Nurs 1999;8:582-8.

30 Lundh U. Family carers. 2: sources of satisfaction among Swedish carers. Br J Nurs 1999;8:647-52.

31 Lundh U. Family carers. 3: coping strategies among family carers in Sweden. Br J Nurs 1999;8:735-40.

32 Wolff JL, Dy SM, Frick KD, et al. End-Of-Life care: findings from a national survey of informal caregivers. Arch Intern Med 2007;167:40-6.

33 Cheng S-T, Mak EPM, Lau RWL, et al. Voices of Alzheimer caregivers on positive aspects of caregiving. Gerontologist 2016;56:451-60.

34 Andrén S, Elmståhl S. Relationships between income, subjective health and caregiver burden in caregivers of people with dementia in group living care: a cross-sectional community-based study. Int $J$ Nurs Stud 2007;44:435-46.

35 Ott $\mathrm{CH}$, Sanders S, Kelber ST. Grief and personal growth experience of spouses and adult-child caregivers of individuals with Alzheimer's disease and related dementias. Gerontologist 2007;47:798-809.

36 Mohamed S, Rosenheck R, Lyketsos CG, et al. Caregiver burden in Alzheimer disease: cross-sectional and longitudinal patient correlates. Am J Geriatr Psychiatry 2010;18:917-27.

37 Ennis N, Rosenbloom BN, Canzian S, et al. Depression and anxiety in parent versus spouse caregivers of adult patients with traumatic brain injury: a systematic review. Neuropsychol Rehabil 2013;23:1-18.

38 Hong G-RS, Kim H. Family caregiver burden by relationship to care recipient with dementia in Korea. Geriatr Nurs 2008;29:267-74.

39 Mackenzie CS, Gekoski WL, Knox VJ. Age, gender, and the underutilization of mental health services: the influence of helpseeking attitudes. Aging Ment Health 2006;10:574-82.

40 Shah AJ, Wadoo O, Latoo J. Psychological distress in carers of people with mental disorders. BJMP 2010;3:a327.

41 de la Maisonneuve C, Oliveira Martins J, Martins JO. The future of health and long-term care spending. OECD Journal: Economic Studies 2015;2014:61-96.

42 Diener E, Pressman SD, Hunter J, et al. If, why, and when subjective well-being influences health, and future needed research. Appl Psychol Health Well Being 2017;9:133-67.

43 ONS. 2011 Census: Aggregate Data, 2020. [data collection]. UK Data Service. SN: 7427.10.5255/UKDA-SN-7427-2.

44 Bottery S, Varrow M, Thorlby R. A fork in the road: next steps for social care funding reform, 2018. Available: www.health.org.uk/news/ social- care-reform-fork-road-says-new-report-embargoed-pressrelease-0001-wed-16-may [Accessed 15 Jun 2020]. 